\title{
مستوى إدراك مرشدي المدارس الثانوية في لواء وادي السير لمفهوم إدارة الأزمات
}

عبدالله فاهد غصاب السكارنة الاردن

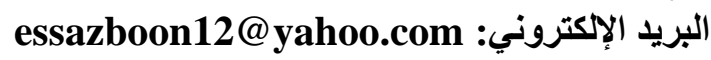

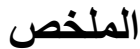

هدفت الدراسة إلى التعرف إلى مستوى إدراك مرشدي المدارس الثانوية في لواء وادي السير للفهوم إدارة الأزمات، وتم استخدام المنهج الوصفي التحليلي، وقد تكون مجتمع الدراسة من جميع المرشدين التربويين العاملين في منطقة وادي السير في الأردن والبالغ عددهم (40) مرشدا تربوياً نم اختبار هم بالطريقة القصدية. وتوصلت نتائج الدراسة إلى أن مستوى إدراك مرشدي المدارس الثانوية لمفهوم إدارة الأزمات كان ضمن فردان

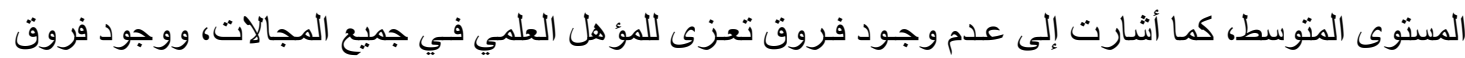

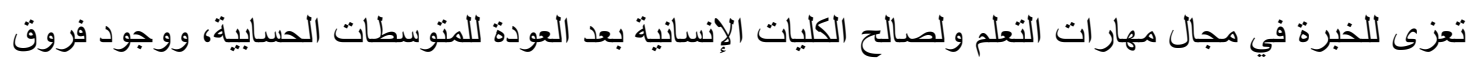
تعزى للنوع الاجتماعي ولصالح الإناث.

الكلمات المفتاحية: إدارة الأزمات، المرشد المدرسي. 


\begin{tabular}{|c|c|c|c|c|}
\hline $\begin{array}{l}2=2 \\
= \\
=\end{array}$ & \multicolumn{3}{|c|}{ 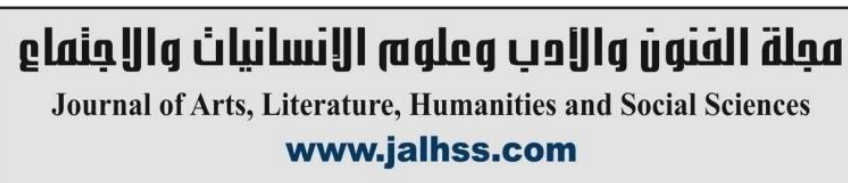 } & \\
\hline$=$ & Volume (72) October 2021 & أكتوبر 2021 أكتو & العدد (72) - الع ال & \\
\hline
\end{tabular}

\title{
The Level of Awareness of Secondary School Counselors in Wadi Al-Seer District of The Concept of Crisis Management
}

\author{
Abdullah Fahed Ghasab Al-Sakarneh \\ Jordan \\ Email: essazboon12@yahoo.com
}

\begin{abstract}
The study aimed to identify the level of awareness of secondary school counselors in the Wadi Al-Seer district of the concept of crisis management, and the descriptive analytical approach was used, The study population consisted of all educational counselors working in the Wadi Al-Seer region in Jordan, who numbered (40) educational counselors who were chosen by the intentional method.

The results of the study concluded that the level of awareness of secondary school counselors of the concept of crisis management was within the average level, and also indicated that there were no differences due to academic qualification in all fields. And there are differences due to experience in the field of learning skills and in favor of the humanities colleges after returning to the arithmetic averages, and there are differences due to gender and in favor of females.
\end{abstract}

Keywords: crisis management, school counselor. 


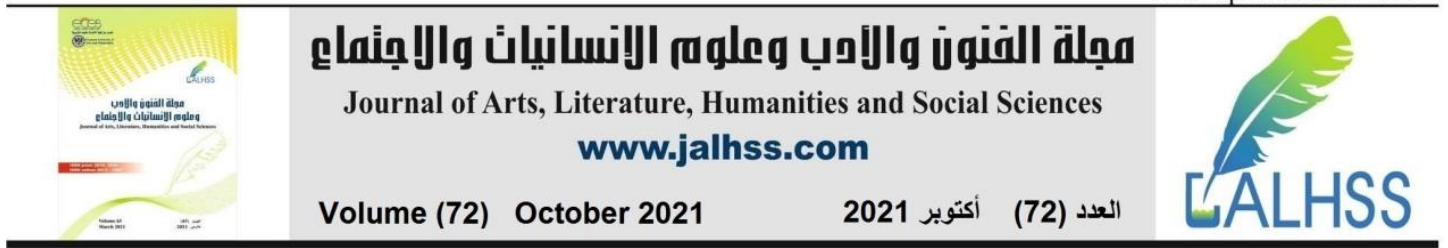

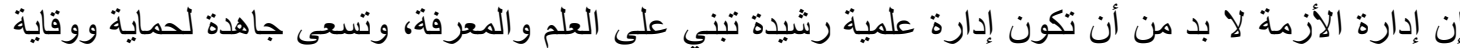

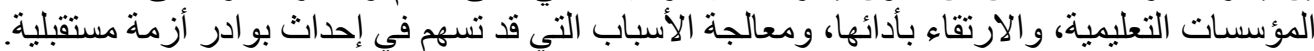

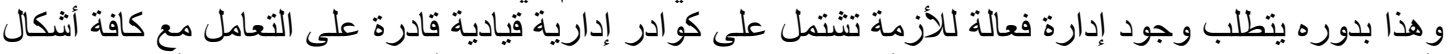

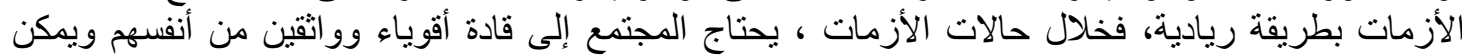

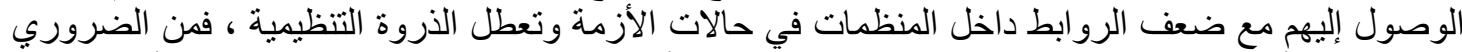

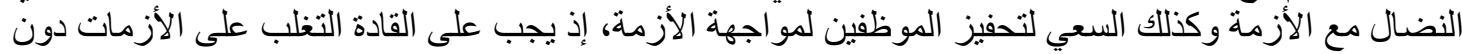

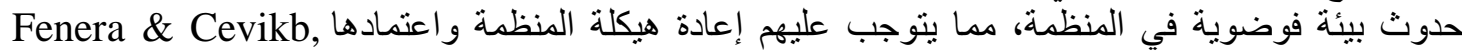

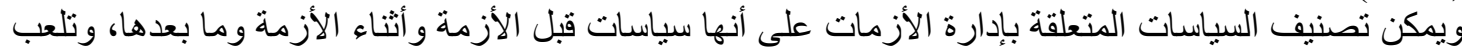

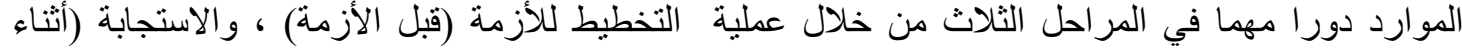

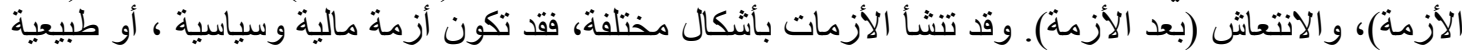

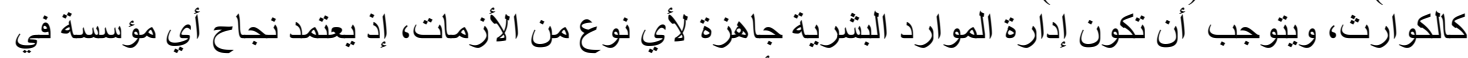

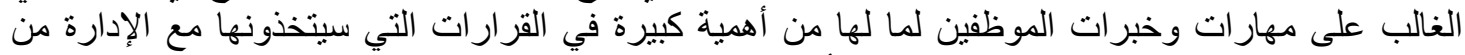

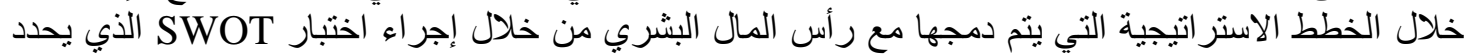

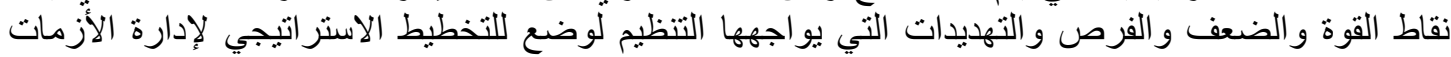

(Vardarlier, 2016)

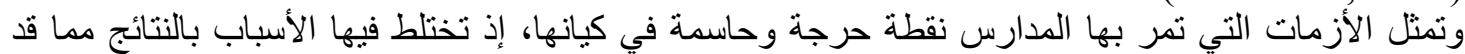

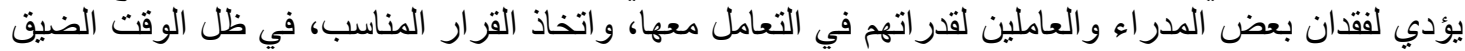

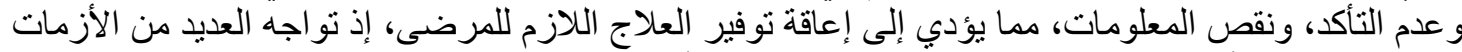

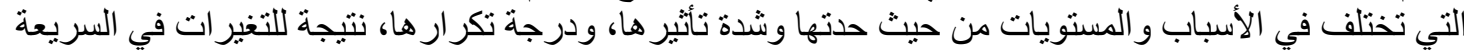

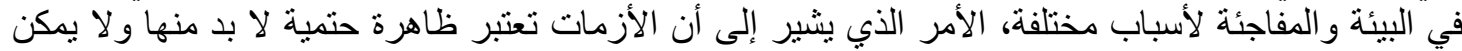

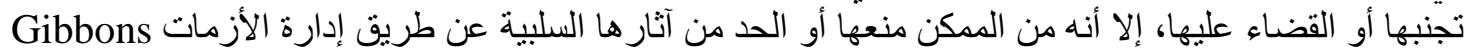

.(et al, 2020)

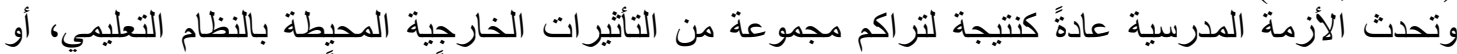

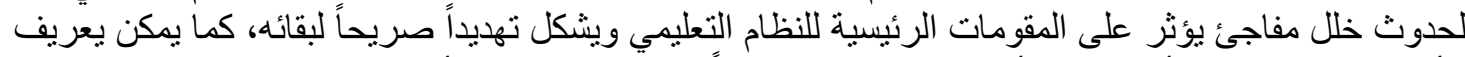

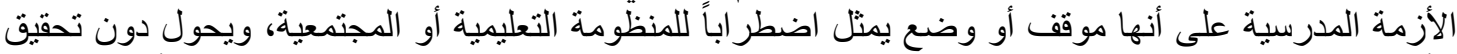

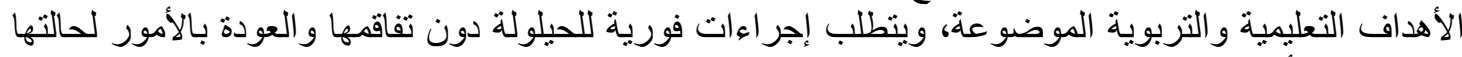

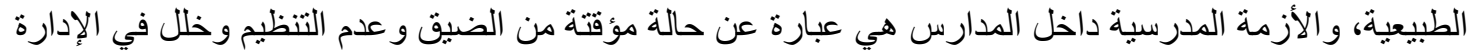

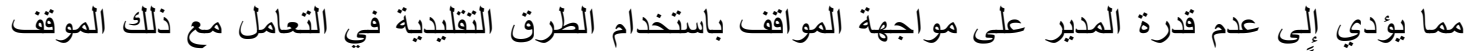

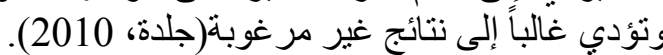

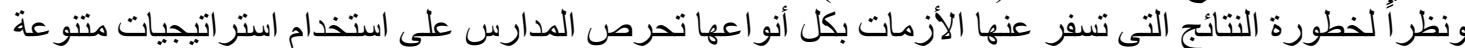

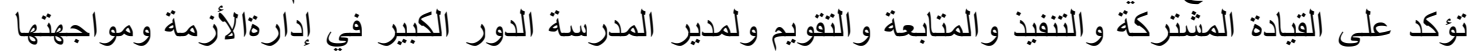

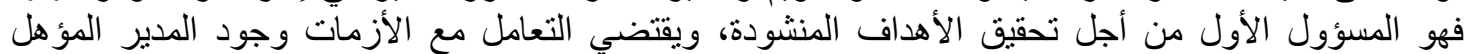

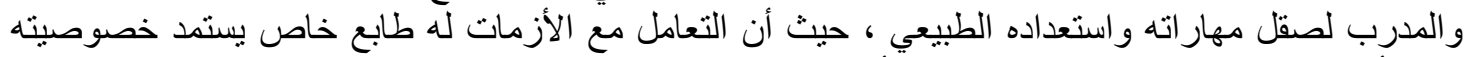

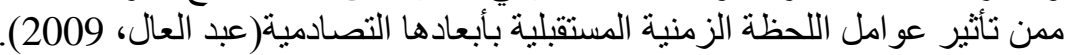

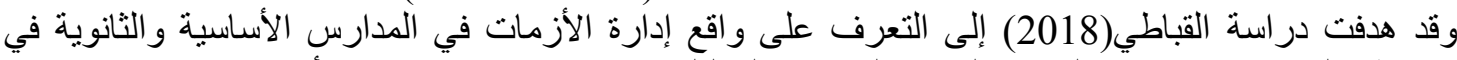

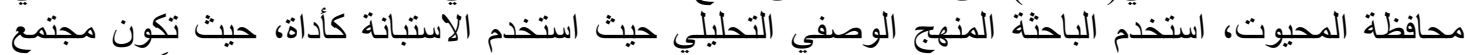

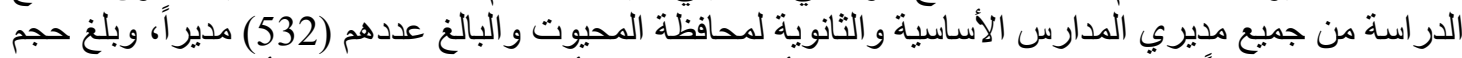

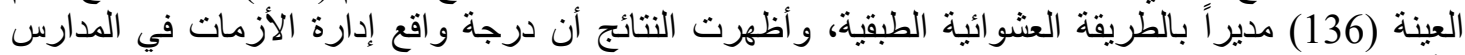

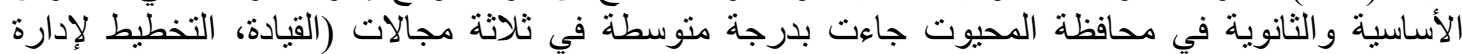

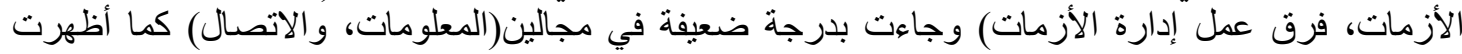

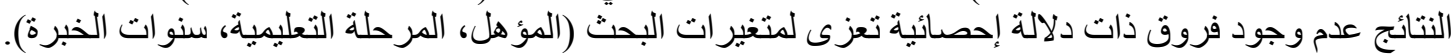




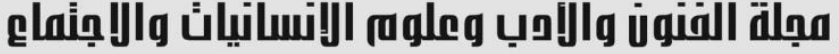

Journal of Arts, Literature, Humanities and Social Sciences www.jalhss.com

Journal of Arts, Literature, Humanities and Social Sciences
www.jalhss.com
$=\quad$ Volume (72)

و هدفت در اسة الحبيس (2016) للتعرف على مستوى إستراتيجية مديري المدارس الثانوية الحكومية الأردنية في

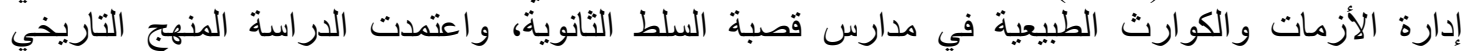

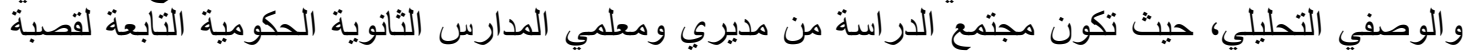

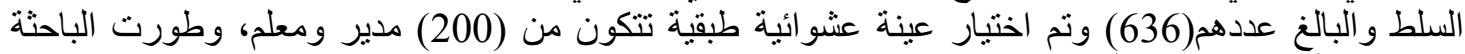

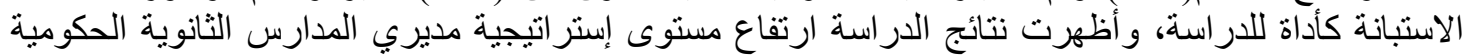

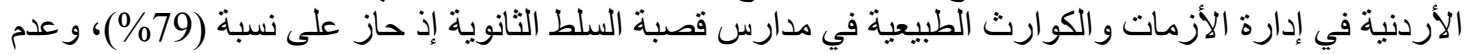

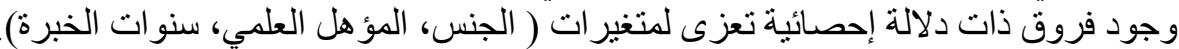

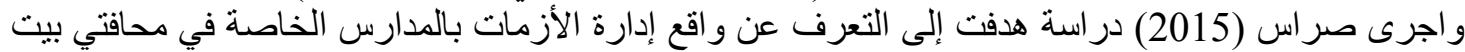

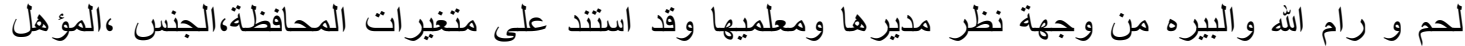

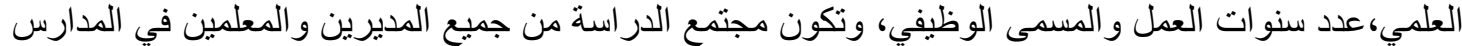

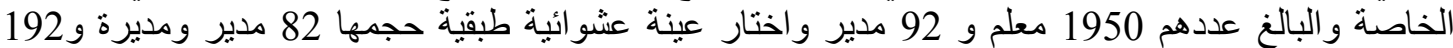

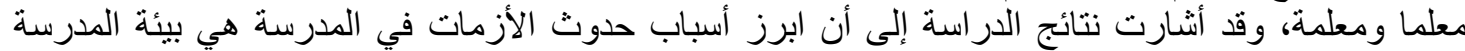

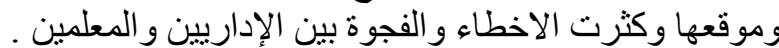

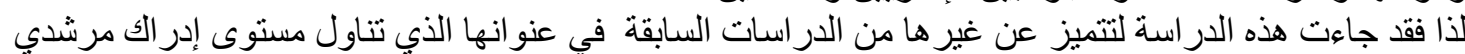

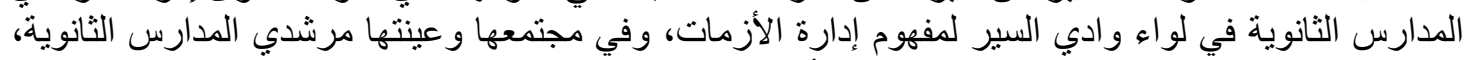

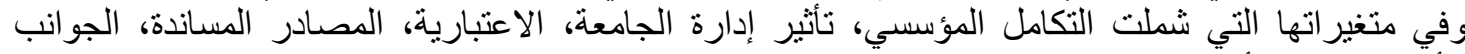
الأكاديمية، المبادأة بالعمل، الروح المعنوية، وآلتي لم تتناولها لئار الدر اسات السابقة بشكل جامع.

مشكلة الاراسـة وأسئلتها

يتميز العصر الحالي بأنه عصر شديد التقلب والته والتغير حيث تشهد العديد من المجتمعات العديد من الأزمات التي والتي

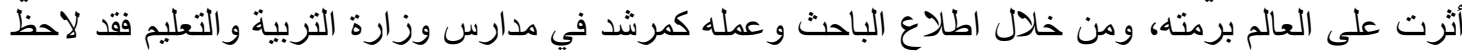

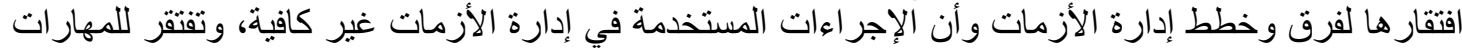

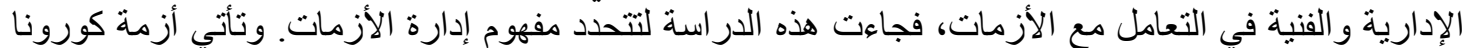

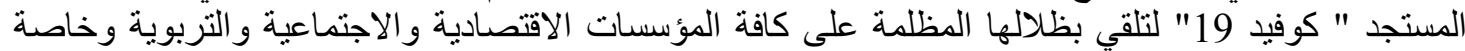

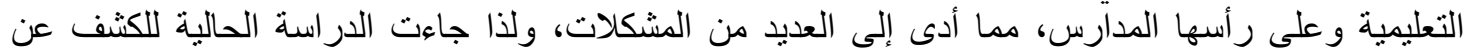

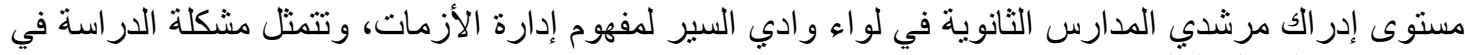

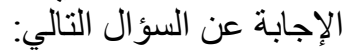

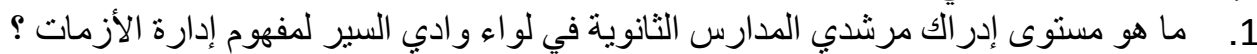

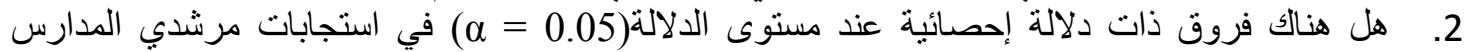

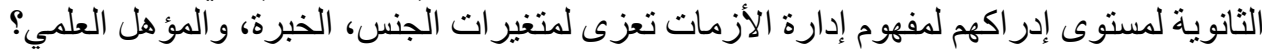

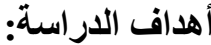
تسعى لتحقيق الأهداف التالية: التعرف إلى مستوى إدر الك مرشدي المدارس الثانوية في لواء و ادي السير لمفهوم إدارة الأزمات.

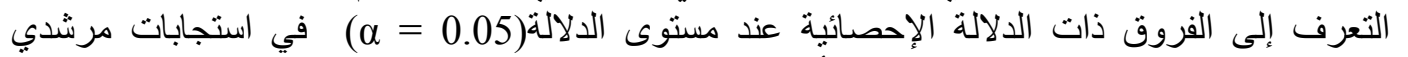

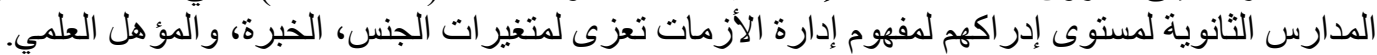

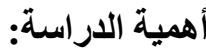
تكمن أهمية هذه الدر اسة في أنها تكثنف عن مستوى إدر الك مرشدي المدارس الثانوية في لو اءو وادي السير للفهوم

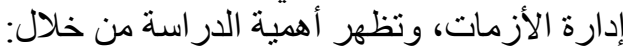
الأهمية العلمية: تعد هذه الدراسة من الدراسات الحديثة في مجال إدارة الأزمات، تتمثل في الأهمية العلمية من

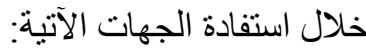
ـ القيادات وصناع القرار في وزاتية وزارة التربية و التعليم.

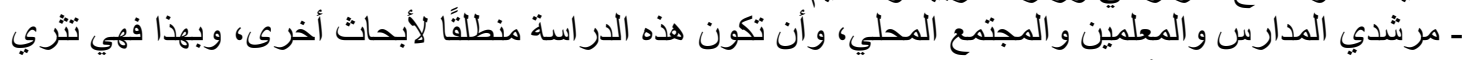

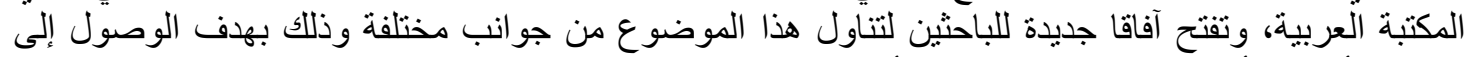

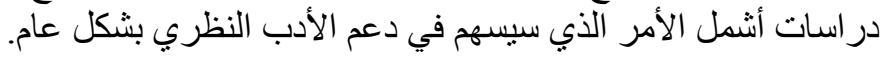




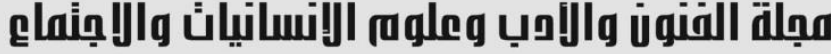

Journal of Arts, Literature, Humanities and Social Sciences www.jalhss.com

\section{Volume (72) October 2021}

أكتوبر 2021

العدد (72) (17)

\section{LALHSS}

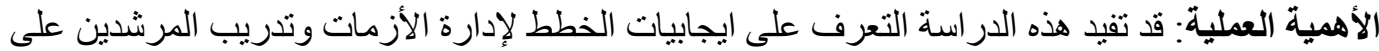

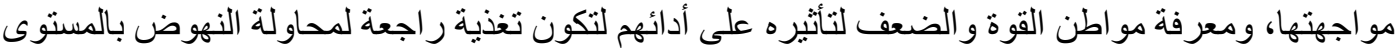

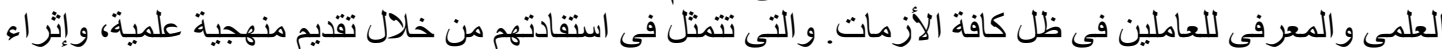
المكتبات المحلية و العربية بإضافة معرفة فلة علمينة.

التعريفات المفاهيمية والإجرائية

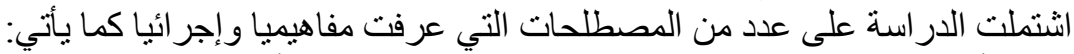

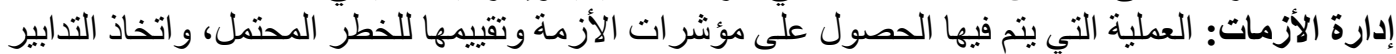
اللازمة وتطبيقها من أجل الوصول إلى الحد الأدنى من الخسائر (Fenera \& Cevikb, 2015 ).

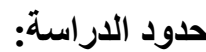
تناولت هذه الدراسة مستوى إدر الك مرشدي المدارس الثانوية في لواءو وادي السير لمفهوم إدارة الأزمات، وذلك

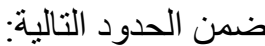
1. الحدود الزمنية: تحددت نتائج الدر اسة بالسياق الزمني الذي أجريت فيه وذلك في الفصل الدراسي الثاني من

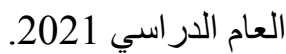
2. الحدود البشرية: تحددت نتائج هذه الدراسة باستجابات مرشدي المدارس الثانوية عينة الدر اسة على فقرات 3. الألحدود المكانية: تقتصر الدر اسة على المدارس الثنانوية في لو اء و ادي السبر.

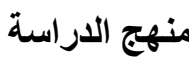
من أجل تحقيق أهداف الدر اسة قام الباحثان باستخدام المنهج الوصفي المسحي لملاءمته وطبيعة الدراسة.

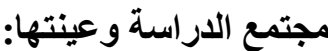
تكون مجتمع الدراسة من جميع المرشدين التربويين العاملين في منطقة وادي السير في الأردن و البالغ عددهم

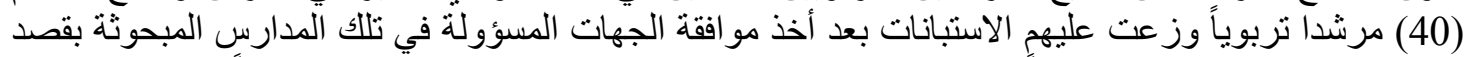

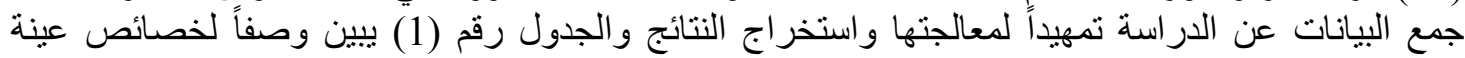
الدراسة وتوز عهم حسب المنغير ات الثخصية و الوظيفية:

\section{(1) الجدول}

توزع أفراد عينة الدراسة حنب خصائصهم الثخصية والوظيفية

\begin{tabular}{|c|c|c|c|}
\hline النسبة المئويةة\% & العدد & فئات المتغيز & المتفير \\
\hline$\% 45$ & 18 & ذكر & \multirow{2}{*}{ النوع الاجتماعي } \\
\hline$\% 55$ & 22 & 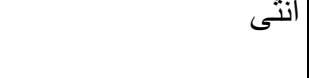 & \\
\hline$\% 10$ & 31 & بكالوريوس & \multirow{2}{*}{ المؤهل العملي } \\
\hline $17.5 \%$ & 0 & در اسات عليا & \\
\hline $10.00 \%$ & 4 & اقل من 5 سنوات & \multirow{3}{*}{ سنوات الخبرة } \\
\hline $27.5 \%$ & 11 & 6-10 سنو ات & \\
\hline $62.5 \%$ & 25 & اكثر من 11 سنة & \\
\hline
\end{tabular}




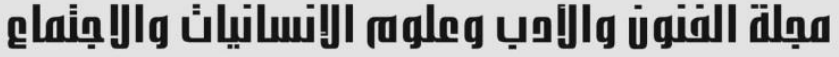

Journal of Arts, Literature, Humanities and Social Sciences www.jalhss.com

Volume (72) October 2021

أكتوبر 2021

العدد (72) (17)

لتحقيق أهداف الدراسة تم تطوير استبانه لقياس مستوى إدراك الك مرشدي المدارس الثنانوية في لواء واء وادي السير

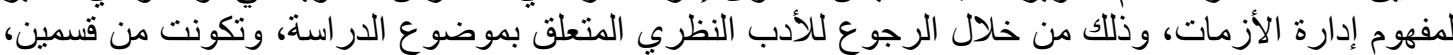

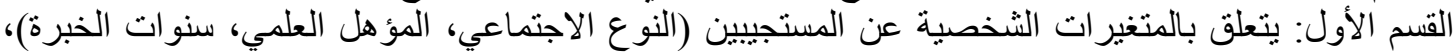

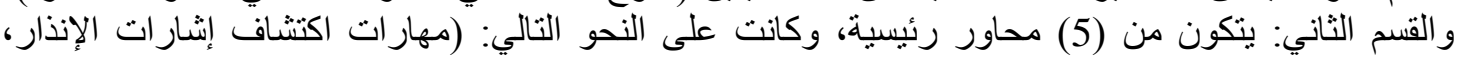

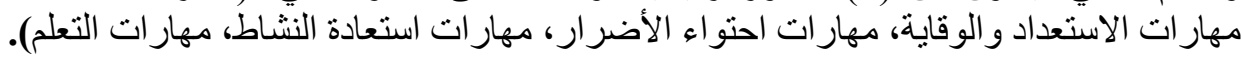

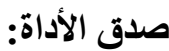
تم التحقق من صدق الأد الأداة باستخدام صدق الدحتوى من خلال عرضها على (10) محكمين من المختصين

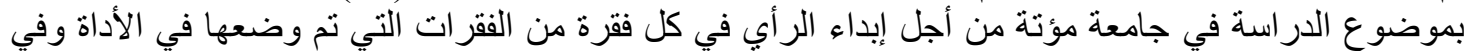

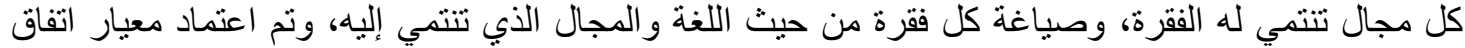
نسبة 80\% من المحكمين على كل فقرة، حيث تم الإبقاء على الفقرة التي اتفق عليها (80\%) من الهي المحكمين.

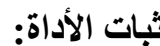

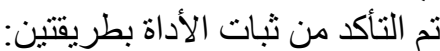
الأولى: ثبات الإعادة بطريقة الاختبار وإعادة الاختبار (Test-Retest) وذلك بنطبيق الاستبانة على عينة

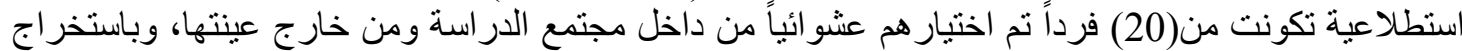
معامل الارنباط (بيرسون) بين مرني التطبيق، وبفارق أسبو عين، وقد بلغ دانغ معامل الثبات المحسوب بهذه الطريقة

الثنانية: ثبات الاتساق الداخلي لفقرات الاستبانة باستخدام طريقة كرونباخ ألفا، وقد بلغ معامل الثبات المحسوب

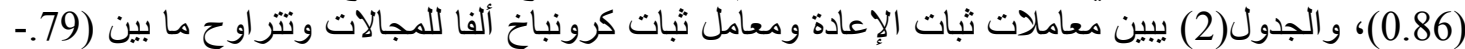

جدول (2)

معاملات الثبات المحسوبة لأداة الاراسة

\begin{tabular}{|c|c|c|}
\hline ثبات كرونباخ ألفا & ثبات الإعادة & 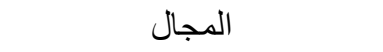 \\
\hline 0.86 & 0.83 & مهار ات اكتشاف إثشار ات الإنذار \\
\hline 0.84 & 0.87 & مهار ات الاستعداد و الوقاية \\
\hline 0.88 & 0.89 & مهار ات احتو اء الأضر ار \\
\hline 0.75 & 0.77 & مهار ات استعادة النشاط \\
\hline 0.83 & 0.84 & مهار ات التعلم \\
\hline & 0.84 & 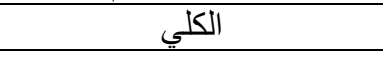 \\
\hline
\end{tabular}

ويلاحظ من خلال الجدول (2) أن قيم معاملات الثبات تعد مقبولة وأن المقياس صالح للاستخدام.

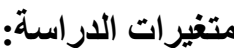

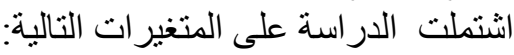
أنتثلت الدر اسة على المتغير ات الأثية:

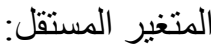

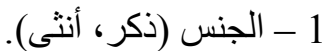
2 - المؤهل العلمي(بكالوريوس، درس، دراسات عليا).

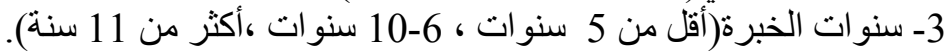

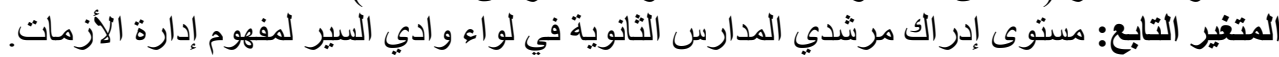




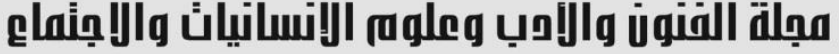

Journal of Arts, Literature, Humanities and Social Sciences www.jalhss.com

نتائج الإحصاء الوصفي لمتغيرات الاراسة:

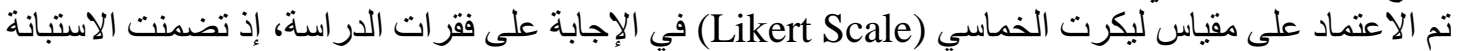

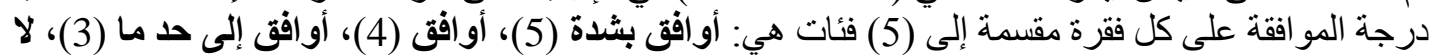

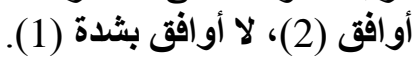

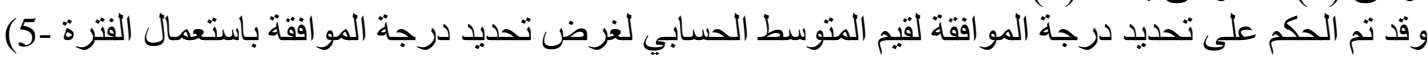

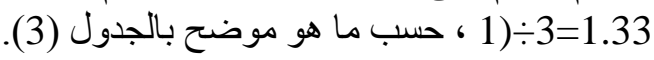

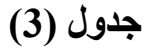

المتوسط الحسابي ودرجة الموافقة

\begin{tabular}{|c|c|}
\hline درجة الموافتــة & المتوسط الحسابــي \\
\hline منخفض & $2.33-1$ \\
\hline منوسط & $3.67-2.34$ \\
\hline مرتفع & $5-3.68$ \\
\hline
\end{tabular}

عرض النتائج ومناقشتها:

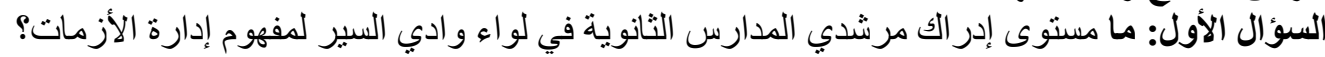

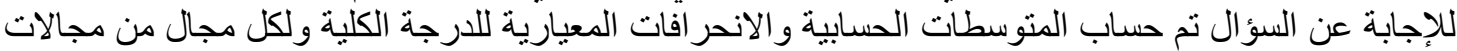

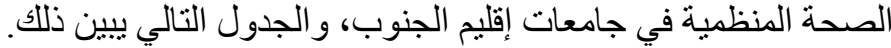
(4) جدول

المتوسطات الحسابية والانحر افات المعيارية مستوى إدراك مرشدي المدارس الثانوية في لواءع وادي السير لمفهوم إدارة الأزمات مرتبة المعارية تنازليا

\begin{tabular}{|c|c|c|c|c|}
\hline المستوى & الترتيب & الانحراف المعياري & المتوسط الحسابي & 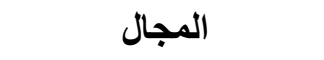 \\
\hline متوسط & 1 & .60 & 3.52 & مهار ات اكتشار الإنذار \\
\hline متوسط & 2 & .73 & 3.51 & مهار ات الاستعداد \\
\hline متوسط & 3 & .84 & 73.4 & مهار اتض احتو اء \\
\hline متوسط & 4 & .75 & 3.38 & مهار ات استعادة النشاط \\
\hline متوسط & 5 & .75 & 63.3 & مهار ات التعلم \\
\hline منوسط & & .59 & 3.40 & الكلي \\
\hline
\end{tabular}

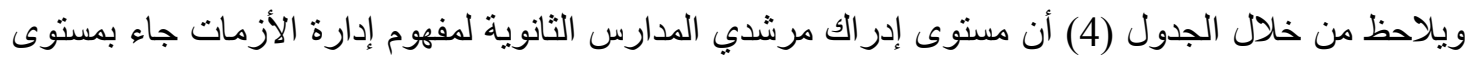
منوسط وبمتوسط حسابي (3.40) و انحر اف معياري(59.)، وقد حل حل مجال مهار ات اكتشاف إثار ات ات الإنذار في المرنبة الأولى وبمستوى منوسط وبمتوسط حسابي بلغ (3.52) و انحر اف معياري (3.

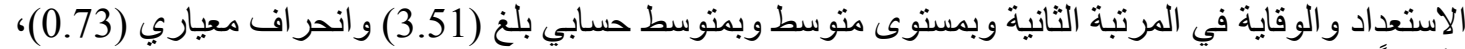

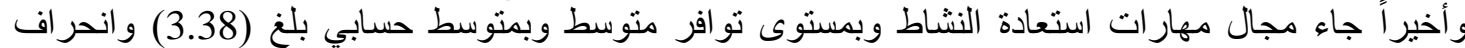

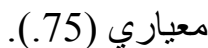
وقد أشتارت النتائج الواردة في الجدول (4) أن مستوى إدر الك مرشدي المدارس الثانوية لمفهوم إدارة الأزمات كان ضمن المستوى المتوسط، وبالتالي هي بحاجة إلى المزيد من العمل من أجل رفع فاعليتها إلى المستوى المرتفع، 


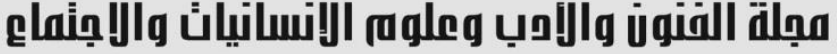

Journal of Arts, Literature, Humanities and Social Sciences www.jalhss.com

\section{Volume (72) October 2021}

أكتوبر 2021

العدد (72) (72)

\section{LALHSS}

وقد يعزى ذلك إلى أن هناك علاقة وثثقة بين المجالات الخمسة لإدارة الأزمات، وتكامل المهمات مع بعضها

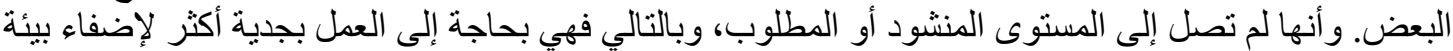
عمل صحية ومناخ إيجابي، وتعكس هذه النتيجة الحاجة لمزيد من الإنفتاح نحو أساليب إدارية معاصرة التيالية لتدعيم

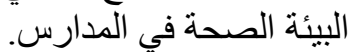

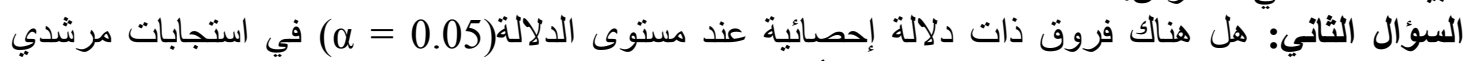

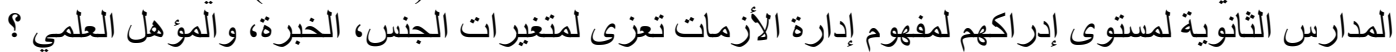

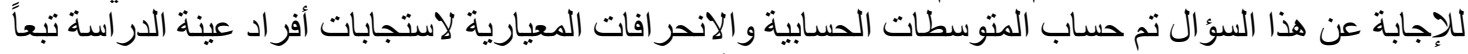
لمتغير ات الدر اسة ( النو ع الاجتماعي، والكلية، و الرتبة الأكاديمية) و الجدول(5) بيين ذللك:

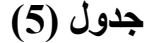

المتوسطات الحسابية والانحرافات المعيارية لمستوى إدراكهم لمفهوم إدارة الأزمات تبعا لمتغيرات النوع الاجتماعي و الكلية و الرتبة الأكاديمية الكفية الكية

\begin{tabular}{|c|c|c|c|c|c|c|c|c|}
\hline \multicolumn{3}{|c|}{ الخبرة } & \multicolumn{2}{|c|}{ المؤهل العلمي } & \multicolumn{2}{|c|}{ النوع الاجتماعي } & \multirow{2}{*}{\multicolumn{2}{|c|}{ المجال }} \\
\hline أكثر من 11 سنة & 6-10 سنوات & سنو من 5 & |در اسات & بكالوريوس & انثى & ذكر & & \\
\hline 101 & 99 & 64 & 129 & 135 & 34 & 230 & العدد & مهار ات \\
\hline 3.44 & 3.53 & 3.64 & 3.54 & 3.49 & 3.75 & 3.49 & المتوسط & اكتشاف \\
\hline .54 & .67 & .56 & .60 & .60 & .62 & .59 & الانحر اف & إلثار اتذار \\
\hline 101 & 99 & 64 & 129 & 135 & 34 & 230 & العدد & مهار ات \\
\hline 3.29 & 3.39 & 3.52 & 3.31 & 3.27 & 3.53 & 3.27 & المنوسط & الاستعداد \\
\hline 1.04 & .69 & .60 & .94 & .74 & .91 & .83 & الانحر اف & و الوقاية \\
\hline 101 & 99 & 64 & 129 & 135 & 34 & 230 & العدد & مهار ات \\
\hline 3.63 & 3.29 & 3.22 & 3.50 & 3.53 & 3.64 & 3.49 & المتوسط & احتو اء \\
\hline .66 & .84 & .71 & .74 & .72 & .65 & .74 & الانحر اف & الأضر ار \\
\hline 101 & 99 & 64 & 129 & 135 & 34 & 230 & العدد الع & مهار ات \\
\hline 3.51 & 3.44 & 3.51 & 3.37 & 3.39 & 3.49 & 3.37 & المتوسط & استعادة \\
\hline .73 & .64 & .85 & .80 & .69 & .81 & .73 & الانحر اف & النشاط \\
\hline 101 & 99 & 64 & 129 & 135 & 34 & 230 & العدد ال العد & مهار ات \\
\hline 3.43 & 3.24 & 3.51 & 3.36 & 3.58 & 3.52 & 3.46 & المتوسط & التعلم \\
\hline .70 & .85 & .60 & .95 & .69 & .77 & .85 & الانحر اف & \\
\hline 101 & 99 & 64 & 129 & 135 & 34 & 230 & العدد & الكل \\
\hline 3.36 & 3.35 & 3.29 & 3.38 & 3.42 & 3.56 & 3.37 & المتوسط & \\
\hline .75 & .71 & .85 & .64 & .54 & .69 & .57 & الانحر اف & \\
\hline
\end{tabular}

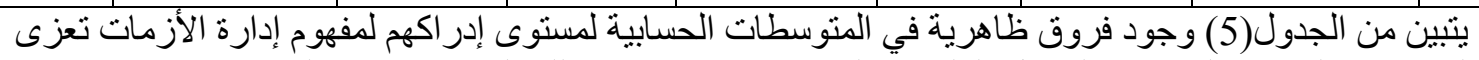

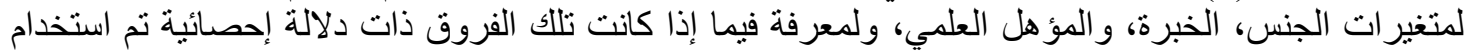
تحليل التباين المتعدد و الجدول(6) يبين ذلك: 


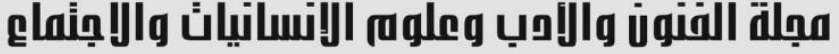

Journal of Arts, Literature, Humanities and Social Sciences

www.jalhss.com

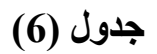

نتائج تحليل التباين المتعدد لدلالة الفروق في مستوى إدراكهم لمفهوم إدارة الأزمات تعزى لمتغيرات الجنس،

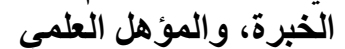

\begin{tabular}{|c|c|c|c|c|c|c|}
\hline مستوى الدلالة & قيمة & المربعات متوسط & درجات & مجموع المربعات & المجالات & مصدر التباين \\
\hline $.016^{*}$ & 55.8 & 2.09 & 1 & 2.09 & مهار ات الثتار الإنذار & \multirow{5}{*}{$\begin{array}{c}\text { النوع الاجتماعي } \\
\text { قيمة هوتلنج } \\
\text { Hotllings trace } \\
\text { 028 }\end{array}$} \\
\hline .084 & 3.00 & 2.20 & 1 & 2.20 & مهار اتل الاستعداد & \\
\hline .240 & 1.39 & .753 & 1 & .753 & مهار الات احتو اء & \\
\hline .306 & 1.05 & .591 & 1 & .591 & مهار ات استعادة النشاط & \\
\hline .470 & .524 & .373 & 1 & .373 & مهار ات التعلم & \\
\hline .541 & .374 & .134 & 1 & .134 & مهار ات اكتشار الإنذار & \multirow{5}{*}{\begin{tabular}{|c|} 
قيمة هوتلنج \\
Hotllings trace \\
039
\end{tabular}} \\
\hline .650 & .206 & .151 & 1 & .151 & مهار اتل الاستعداد & \\
\hline .770 & .086 & .046 & 1 & .046 & مهار الات احتو اء & \\
\hline .847 & .037 & .021 & 1 & .021 & مهار ات استعادة النشاط & \\
\hline $.039 *$ & 4.30 & 3.06 & 1 & 3.06 & مهار ات التعلم & \\
\hline .068 & 2.71 & .972 & 2 & 1.94 & مهار ات الكتشاف الإنذار & \multirow{5}{*}{ 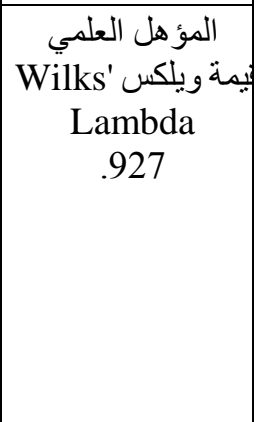 } \\
\hline .380 & .972 & .712 & 2 & 1.42 & مهار اتو الاستعداد & \\
\hline .244 & 1.42 & .769 & 2 & 41.5 & مهار اتضر احتو اء & \\
\hline .059 & 72.8 & 11.6 & 2 & 23.2 & مهار ات استعادة النشاط & \\
\hline \multirow[t]{6}{*}{.638} & .450 & .320 & 2 & .641 & مهار ات التعلم & \\
\hline & & .358 & 925 & 90.916 & مهار اتثات الانتشاف & \multirow[t]{5}{*}{ الخطأ } \\
\hline & & .732 & 925 & 185.981 & مهار ات الاستعداد & \\
\hline & & .542 & 925 & 137.594 & مهار اتض احتواء & \\
\hline & & .560 & 925 & 142.337 & مهار ات استعادة النشاط & \\
\hline & & .711 & 925 & 180.706 & مهار ات التعلم & \\
\hline
\end{tabular}




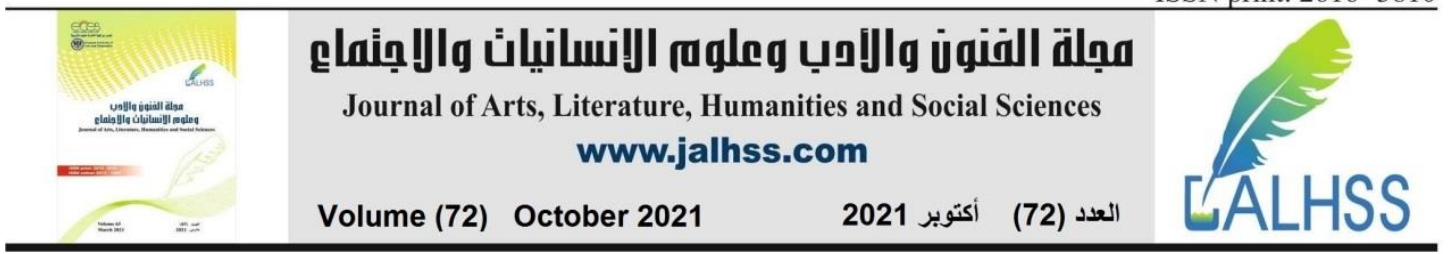

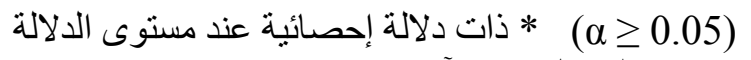
يتبين من الجدول (6) الآتي:

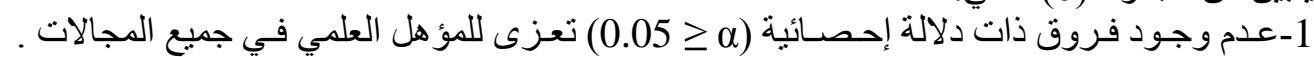

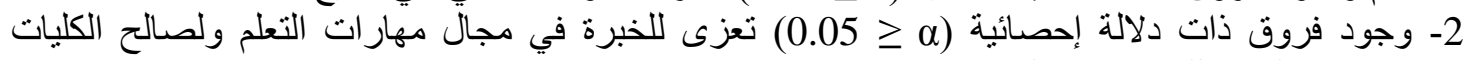
الإنسانبة بعد العودة للمتوسطات الحسابة دابية.

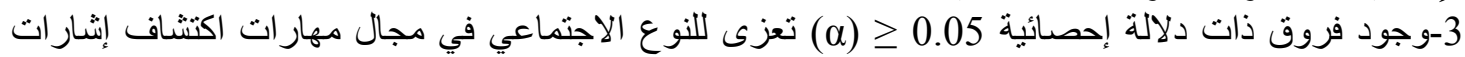

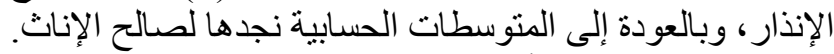

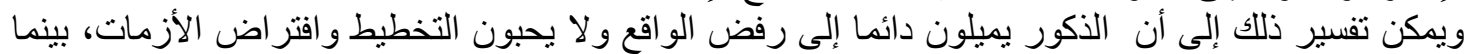

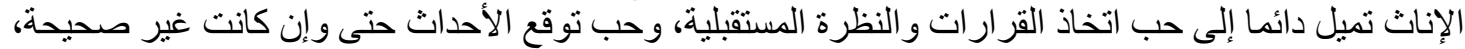

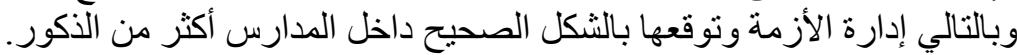

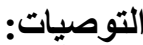

اعتماداً على النتائج السابقة يمكن تقديم التوصيات التالية:

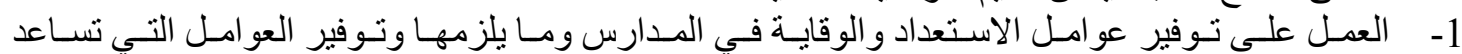

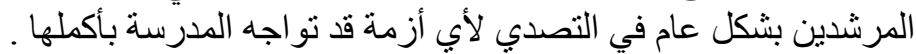

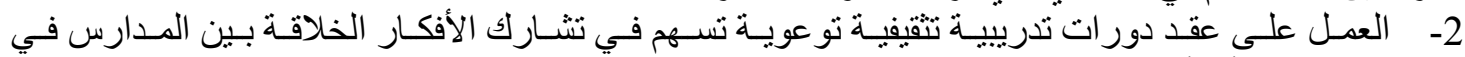

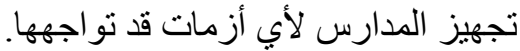
3- إجر اء المزيد من الدارسات ذاست ذات الصلة بإدارة الأزمات على المدارس الأخرى، والمؤسسات التعليمية المختلفة، في ظل ندرة الدراسات المحلية في هذا المجال.

المراجع

1. جلده ، سليم ـ (2010) ـ الإستر اتيجيات الحديثة لإدارة الأزمات في ظل عالم متغير ، ط1 ، عمان ، دار

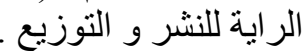

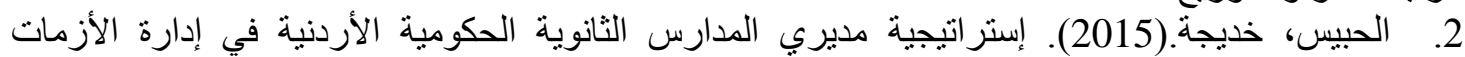

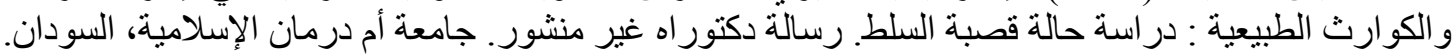

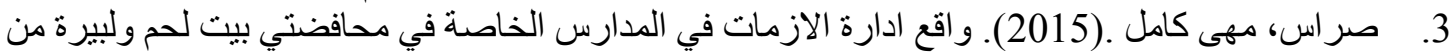

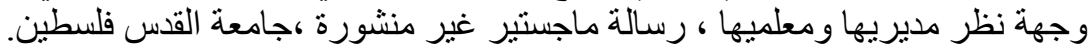

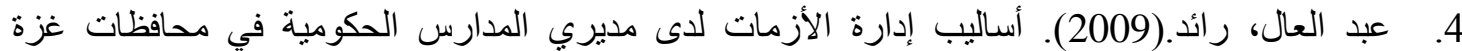

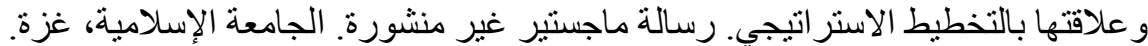

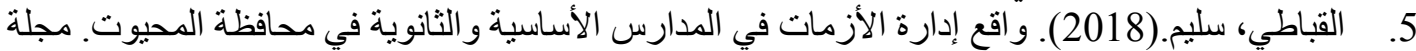
الدر اسات الاجتماعية ، 24(1)، 33 -54.

6. Fenera , Tugce, Cevikb, Tugce(2015). Leadership in Crisis Management: Separation of Leadership and Executive Concepts. Procedia Economics and Finance, 26( 1$), 695-701$.

7. Gibbons, John, Forman, Siobhan, Keogh, Peter, Curtin, Paul, Kiely, Ruth, Leary, Geraldine, Skerritt, Conor, Sullivan, Kathy, Synnott, Keith, Cashman, James (2020). Crisis change management during COVID-19 in the elective orthopaedic hospital: Easing the trauma burden of acute hospitals . The Surgeon, 8(1), 1-8.

8. Vardarliera, Pelin(2016). Strategic approach to human resources management during crisis. Procedia - Social and Behavioral Sciences, 235 ( 1 ), 463 - 472. 